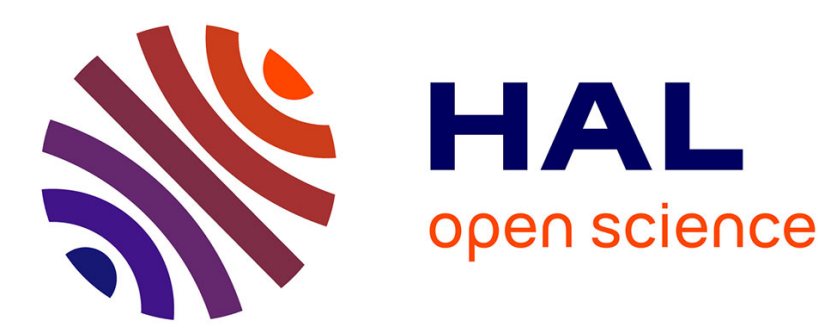

\title{
Seismic network design to detect felt ground motions from induced seismicity
}

John Douglas

\section{To cite this version:}

John Douglas. Seismic network design to detect felt ground motions from induced seismicity. Soil Dynamics and Earthquake Engineering, 2013, 48, pp.193-197. 10.1016/j.soildyn.2013.01.030 . hal00790983

\section{HAL Id: hal-00790983 https://hal-brgm.archives-ouvertes.fr/hal-00790983}

Submitted on 21 Feb 2013

HAL is a multi-disciplinary open access archive for the deposit and dissemination of scientific research documents, whether they are published or not. The documents may come from teaching and research institutions in France or abroad, or from public or private research centers.
L'archive ouverte pluridisciplinaire HAL, est destinée au dépôt et à la diffusion de documents scientifiques de niveau recherche, publiés ou non, émanant des établissements d'enseignement et de recherche français ou étrangers, des laboratoires publics ou privés. 


\title{
Seismic network design to detect felt ground motions from induced seismicity
}

\author{
John Douglas \\ BRGM - DRP/RSV, 3 avenue C. Guillemin, BP 36009, 45060 ORLEANS Cedex 2, \\ France. Tel: +33 (0)2.38.64.30.30. Fax: +33 (0)2.38.64.47.38.
}

\begin{abstract}
Human activities, such as fluid injection as part of the stimulation of an enhanced geothermal system (EGS) for heat and power production, can cause damaging earthquake ground motions. A difficulty in quickly settling or rejecting insurance claims to the policy of the operator of the EGS is the lack of ground truth on the observed shaking at sites of reported damage. To overcome this problem a local seismic network could be installed prior to injection to constrain the ground-motion field at points of potential damage. Since the installation and maintenance of seismometers is costly there is an incentive to keep the number of instruments to a minimum. In this short communication, ground-motion fields are simulated and receiver operating characteristic analysis conducted to guide decisions on the number of sensors required to obtain a certain confidence in the rate of false alarms and missed detections. For densities of 10-20 instruments per $\mathrm{km}^{2}$ the ability to estimate potentially-damaging ground motions is reasonable but associated with a significant chance of missed detections and false alarms. If an EGS operator
\end{abstract}

Email address: j.douglas@brgm.fr (John Douglas) 
or regulatory authority does not want to accept such chances then network densities of 50-100 instruments per $\mathrm{km}^{2}$ are required and even in this case the exceedance/non-exceedance of a certain ground-motion threshold cannot be completely constrained.

Keywords: seismic networks, geothermal power production, induced seismicity, spatial correlation, enhanced geothermal systems, earthquake ground motions, receiver operating characteristic

\section{Introduction}

Heat and power production via enhanced geothermal systems (EGS) is an attractive low-carbon renewable energy source and a number of tests of this technology are operating (e.g. Soultz-sous-Forêts, France) or are in the planning stage (e.g. Newberry, USA). In an EGS the permeability of a geothermal reservoir is enhanced using hydraulic stimulation, which purposely induces micro-earthquakes but because of existing (tectonic) may also trigger larger shocks [1]. As discussed by Gardini [2], during the Deep Heat Mining (Basel, Switzerland) project a mainshock of magnitude $M_{L} 3.4$ was triggered along with thousands of smaller earthquakes. The shaking from these tremors were cause for concern to the local population and led to the shutdown of this project and insurance claims amounting to more than $\$ 9$ million for minor building damage (e.g. non-structural cracking). A difficulty in resolving these insurance claims is knowing whether the observed building damage was actually due to shaking caused by earthquakes induced or triggered by the EGS or were actually pre-existing and only noticed after the tremors. Resolution of this question requires information on two aspects: the earth- 
quake shaking that the local building stock was subjected to due to the EGS project, and the vulnerability of the buildings to this shaking, which could be modelled using appropriate fragility curves. The second of these topics is not discussed here, although fragility curves to predict cracking from highfrequency ground motions from shallow induced seismicity is a topic that has not be widely researched and hence is ripe for investigation. This short communication concerns the ability to recover the true earthquake shaking, characterized by a scalar intensity measure (e.g. peak ground velocity, PGV) that is useful for the prediction of building damage, based on measurements from a local seismic network.

The advantage of having a local seismic network in a population centre close to an area of geothermal power production is shown by a recent study concerning the Icelandic village of Hvergerdi, which is monitored by the dense network known as ICEARRAY [3]. These instruments were used to demonstrate that the pseudo-spectra accelerations in the village due to some recent induced seismicity (including an $M_{L} 3.8$ earthquake) from a nearby (at $11 \mathrm{~km}$ ) geothermal power plant, Hellisheidi, were close to and sometimes surpassed the codified design spectral accelerations for the majority of the building stock.

The aim of this study is to provide guidance on the number of instruments required to obtain a certain detection rate of an intensity measure surpassing a given threshold. It is based on the simulation of local ground-motion fields consistent with those observed from induced seismicity. These simulations are discussed in the following section. The subsequent section presents the method (kriging) used to recover this ground-motion field based on obser- 
vations at a limited number of (simulated) instruments. The penultimate section analyzes the results of thousands of such simulations using the approach known as receiver operating characteristic (ROC) analysis to draw graphs allowing the number of required instrument density to obtain certain true and false positive rates to be estimated. This short communication ends with some brief conclusions and suggestions for future research.

\section{Simulated ground-motion fields}

The procedure presented by Strasser and Bommer [4, pp. 2625-2626] is used to simulated the spatially-correlated ground-motion fields taking into account the within(intra)-event variability. Between(inter)-event variability is considered in the ground-motion fields by the inclusion of event terms within the PGV computation computed using the between-event standard deviation $(\tau)$ and the normal distribution. Similar approaches have been used in previous studies [e.g. 5]. Since the aleatory variabilities associated with the GMPE used here are very large the ground-motion fields show great differences and hence many runs are required to obtain stable results from this analysis.

The empirical ground-motion prediction equation (GMPE) derived by Douglas et al. [6] for PGV based on thousands of records from microseismicity in geothermal zones is used here to obtain the deterministic groundmotion field assuming a point source, which is a common assumption for small earthquakes even though the causative rupture will have length of a few hundreds of metres. This equation, for a rock site based on a generic velocity profile, is (in terms of $\mathrm{cm} / \mathrm{s}$ and hypocentral distance, $r_{h y p}$ ): 


$$
\log _{10} y=-2.3426+0.8526 M_{w}-1.4048 \log _{10}\left(\sqrt{r_{h y p}^{2}+2.9330^{2}}\right)-0.013 r_{h y p}
$$

with a between-event standard deviation of $\tau=0.6746$ and a within-event standard deviation of $\phi=0.4467$. The impact of the high value of $\phi$ on the results was tested and within a reasonable range for this component of the aleatory variability it does not have a significant influence on the detection rates so it is not considered further.

This deterministic ground-motion field is perturbed by the addition of random field derived from a multivariate normal distribution based on an exponential correlation function with a correlation length $h_{0}$ (i.e. $\exp \left(-h / h_{0}\right)$, where $h$ is the separation distance between points of interest) and a standard deviation equal to the within-event variability of the selected GMPE. The exponential correlation function has been found to fit the observed spatial correlation of earthquake ground motions but $h_{0}$ appears to vary with the structural period, geographical region and earthquake [e.g. 5, 7]. To consider the observed range of $h_{0}$ two values are considered here: 5 and $20 \mathrm{~km}$. In addition, two end-members: $h_{0}=0.001$ (no correlation between sites) and $h_{0}=10000 \mathrm{~km}$ (complete correlation between sites) are simulated to understand the role of this key parameter, which is poorly known particularly for induced seismicity. The spatial correlation of ground motions from small earthquakes could be higher than for larger earthquakes since the point source assumption is more appropriate but on the other hand the short seismic wavelengths from small earthquakes could mean that the spatial variability is large because of scattering due to a heterogeneous crust. 
A moment magnitude $\left(M_{w}\right)$ of 3.5 and a focal depth of $3 \mathrm{~km}$ are assumed for the scenario earthquake because EGS operators would hope to contain the seismicity to smaller events and hence such a scenario could be considered a worst case for most projects. An area of $1 \mathrm{~km} \times 1 \mathrm{~km}$ above the injection well is considered for these calculations with a resolution of $20 \mathrm{~m}$ (i.e. a grid of $50 \times 50=2500$ points) and the earthquake epicentre in the centre of this zone. A building density of 1000 houses per $\mathrm{km}^{2}$, corresponding to a European suburban area, is assumed. The number of instruments co-located with the houses is varied between 10, roughly corresponding to the density of the ICEARRAY [8], and 100, which is much higher than any existing strong-motion array [9] and corresponds to an instrument every $100 \mathrm{~m}$. A PGV threshold of $7.4 \mathrm{~mm} / \mathrm{s}$ is considered because this corresponds to the 2nd-percentile (median minus two standard deviation) PGV for an Modified Mercalli intensity of $\mathrm{V}$ (slight cracking of plaster possible) according to the ground-motion intensity conversion equations (GMICEs) of Worden et al. [10]. These GMICEs are used because they are the most recent ones available and they are based on a large database of observations (roughly 200000 intensity-PGV pairs).

An example simulated ground-motion field with the associated houses and sensors is presented in Figure 1 for $h_{0}=5 \mathrm{~km}$, showing the considerable spatial variation to be expected in earthquake ground motions that is not explained by the distance from the source. It is this spatial variation in shaking that makes the estimation of ground motions at the location of a house based on measurements at surrounding instruments prone to large uncertainties. 

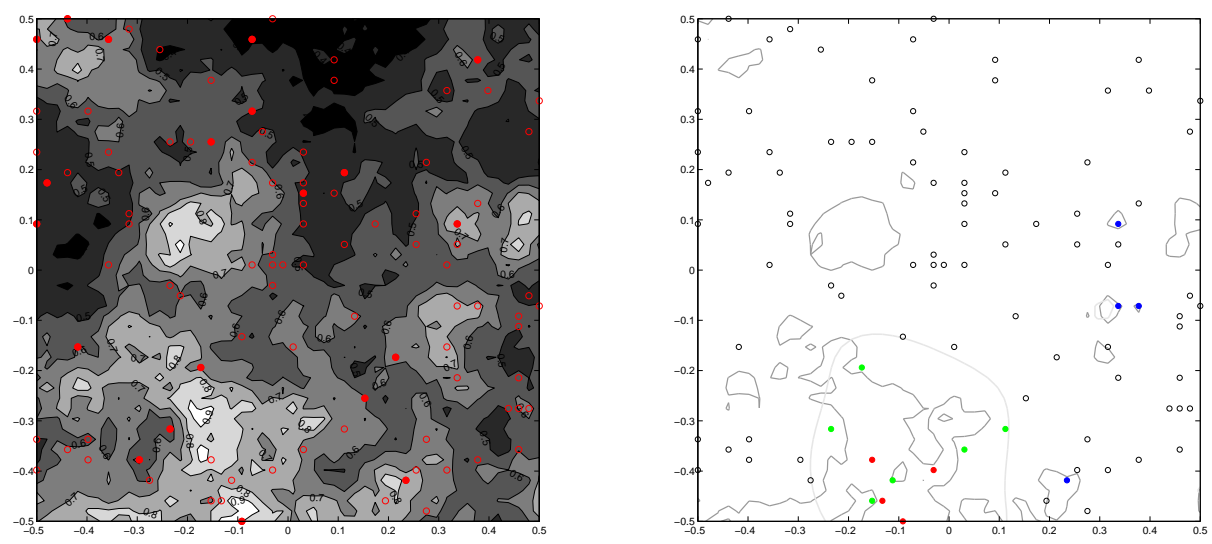

Figure 1: Left: Example ground-motion field simulated for this study, with the simulated locations of 100 houses (unfilled circles) and 20 instruments (filled circles). Right: Simulated (dark grey) and recovered (light grey) contour of PGV threshold using the measurements at the 20 instruments and the relations between these thresholds at the 100 considered houses colour-coded thus: red, true positive; blue, false negative; green, false positive; and black (unfilled), true negative. Note that 100 rather than 1000 houses are assumed to more clearly show the results. 


\section{Recovery of observed ground motion at sites of interest}

In this section it is assumed that all that is available to estimate the ground-motion field are the PGV observations at the simulated sensors. From these measurements the PGVs estimated at the considered houses will be computed and checked against the considered threshold. The geostatistical technique known as kriging with a trend is used for this purpose. Kriging is a commonly-used technique for the interpolation of measurements at geographically-distributed locations and it has been used in ground-motion estimation in a number of studies [e.g. 11, 12, 13]. The trend model used as part of this procedure accounts for the overall distance decay that on average is present in earthquake ground motions - it is assumed here that the earthquake location is precisely known (this is reasonable given that the earthquakes are assumed to be induced in an EGS reservoir that is monitored by a local seismic network). This technique roughly corresponds to the inverse of the method used to simulate the ground-motion field because kriging makes use of a spatial correlation model, for which here an exponential model is assumed for consistency with the simulations. A comparison between the simulated and recovered ground-motion thresholds at the considered houses is shown in Figure 1. It should be noted that the same value of $h_{0}$ is assumed as for the simulations - the impact of this assumption is investigated below. In general this procedure leads to a high correlation between the simulated and recovered PGVs at all grid points, particularly when the density of instruments is large (Figure 2). 

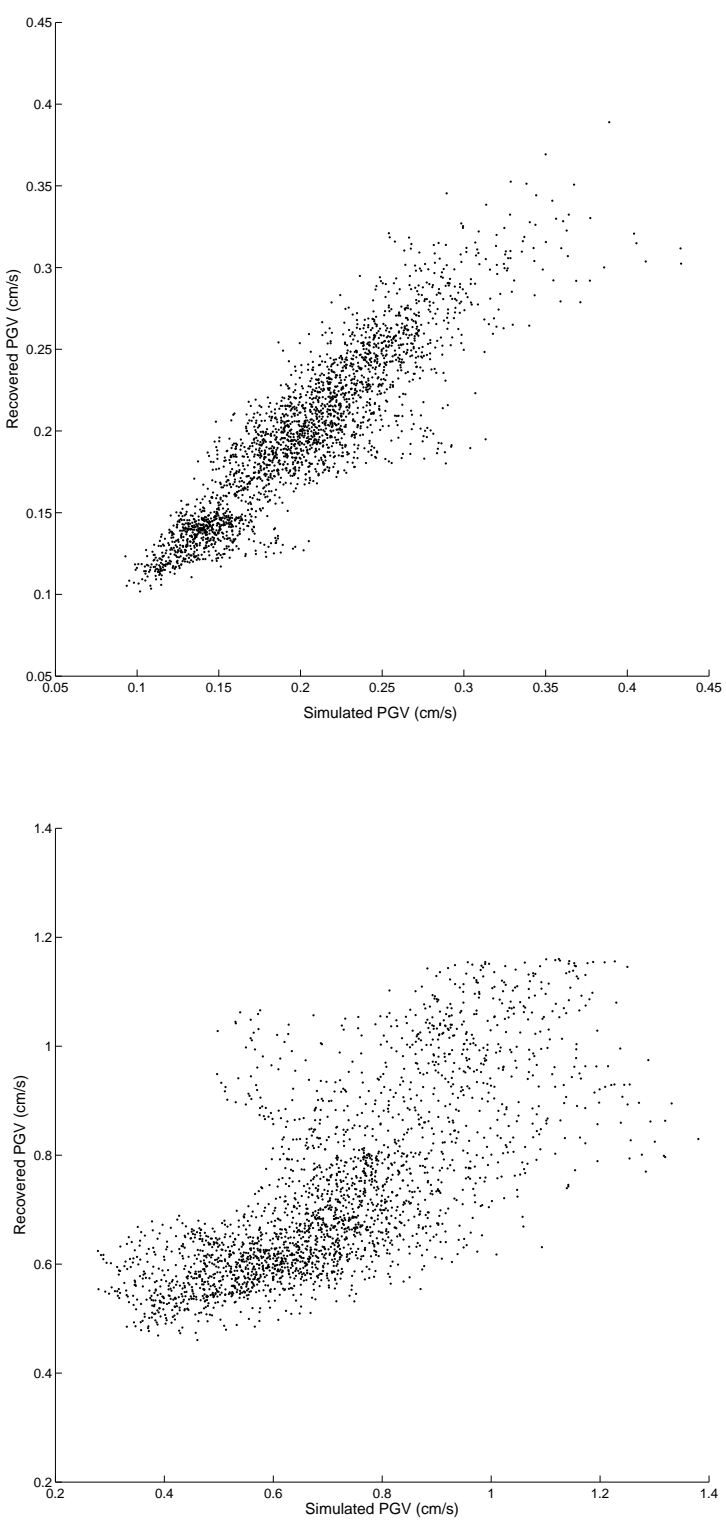

Figure 2: Top: Simulated versus recovered PGVs at the 2500 grid points for an example ground-motion field assuming 200 instruments. Bottom: Simulated versus recovered PGVs at the 2500 grid points for an example ground-motion field assuming only 20 instruments. 


\section{Receiver operating characteristic}

In this study, the interest is in the ability to predict the surpassing or not of a ground-motion threshold indicating a possibly damaging level of shaking at houses within the epicentral zone. A useful tool in such a situation is ROC analysis in which the rates of the four possible outcomes of a prediction are considered. These four outcomes are: true positive (observed and predicted PGV both above threshold), false positive (false alarm, i.e. predicted PGV above threshold but observed PGV actually below threshold), true negative (observed and predicted PGV both below threshold) and false negative (missed detection, i.e. observed PGV above threshold but predicted PGV below threshold). A good local network would be one where the true positive and negative rates were maximized with respect to the false positives and negatives because this would allow, for example, the insurance claims for building damage to be quickly resolved.

To construct a ROC curve the true positive rate is plotted against the false positive rate. The better the prediction method the closer the ROC curve is to the upper left hand corner of the graph $(0,1)$, i.e.: a true positive rate of $100 \%$ and a false positive rate of $0 \%$ (no false alarms or missed detections). The closer the ROC curve is to the 45 degree line the worse the detection technique. These curves, therefore, provide a useful way of comparing the ability of different densities of sensors to assess the PGVs at sites of interest. The impact of increasing the density of instruments is shown in Figure 3, where it can be seen that increasing the number of sensors moves the results of the ROC analyses away from the 45 degree line and towards the topleft corner. Because of the large variation in the ground-motion fields and 


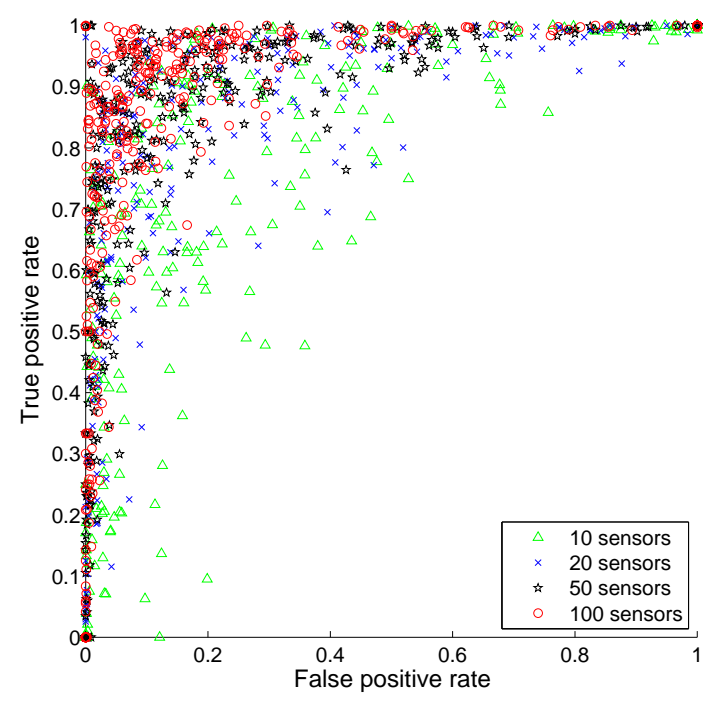

Figure 3: Results of ROC analyses for four different densities of instruments: 10, 20, 50 and 100 within a $1 \mathrm{~km}^{2}$ zone assuming a spatial correlation length $h_{0}=5 \mathrm{~km}, M_{w} 3.5$ and a PGV threshold of $7.4 \mathrm{~mm} / \mathrm{s}$.

the random distribution of houses and instruments the results of the ROC analysis do not form a curve but show considerable dispersion. In the extreme case of a seismometer in every house the ROC curve would correspond to a point at $(0,1)$ indicating a perfect detection rate and no false alarms.

Modification of the size or depth of the scenario earthquake or the PGV threshold would increase or decrease the absolute number of samples above or below the considered limit without necessarily changing the ability of the network to discriminate between potential damaging amplitudes or not. For example, Figure 4 shows the results of a ROC analysis using the same procedure but assuming a smaller magnitude $\left(M_{w} 3\right)$ and a lower PGV threshold, $2.2 \mathrm{~mm} / \mathrm{s}$, corresponding to the 2nd-percentile (median minus two standard deviation) PGV for an Modified Mercalli intensity of IV (microcracks in 


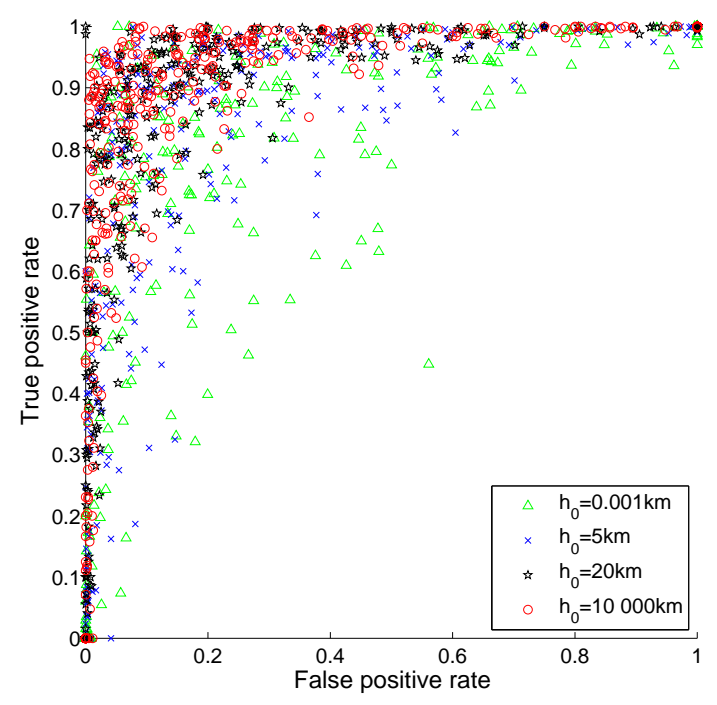

Figure 4: Results of ROC analyses for four different densities of instruments: 10, 20, 50 and 100 within a $1 \mathrm{~km}^{2}$ zone assuming a spatial correlation length $h_{0}=5 \mathrm{~km}, M_{w} 3$ and a PGV threshold of $2.2 \mathrm{~mm} / \mathrm{s}$. plaster possible) again using the same GMICEs as above [10]. By comparing

Figures 3 and 4 it can be seen that the rates of true and false positives are almost unchanged by the modification of the scenario and the threshold.

Apart from the instrument density, a key parameter affecting the ROC results is the correlation length $h_{0}$. In Figure 5 the impact of varying this parameter is shown assuming 20 instruments. As expected, as the value of $h_{0}$ increases (PGVs at neighbouring points are increasing correlated) the ROC results tend to the top left corner, i.e. better detection rate with fewer false alarms. When there is no correlation between neighbouring points $\left(h_{0}\right.$ very small) the ground-motion field cannot be recovered from the available measurements and the question of whether PGV surpassed the considered threshold becomes a matter of complete chance. This is indicated by the ROC 


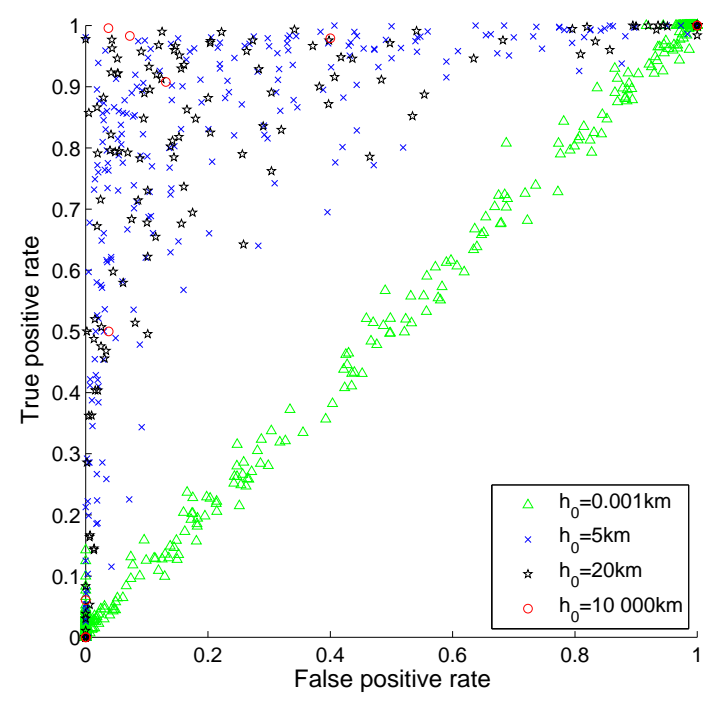

Figure 5: Results of ROC analyses for four different values of $h_{0}$ : 0 (no spatial correlation), 5, 20 and $10000 \mathrm{~km}$ (all points perfectly correlated) assuming 20 instruments.

curve falling along the 45 degree line in Figure 5. When ground motions are perfectly correlated spatially ( $h_{0}$ is very large) the ground-motion field can be recovered at all points based on only a few measurements that enable the decay with distance to be estimated. This leads to a ROC curve that falls in the top left hand corner of the graph (Figure 5). The reason why there appears to be far fewer points for $h_{0}=10000 \mathrm{~km}$ than for the other three cases is that almost all of the points overlap since the ground-motion fields only differ due to the between-event variability. There is generally a small difference in the results when $h_{0}=5$ or $h_{0}=20 \mathrm{~km}$.

One assumption made above is that the same $h_{0}$ is assumed to simulate the ground-motion field and to reconstruct the field based on PGVs at the hypothetical instruments. In reality, however, $h_{0}$ is uncertain. To investigate the impact of not knowing $h_{0}$ an additional test is conducted. ROC analyses 


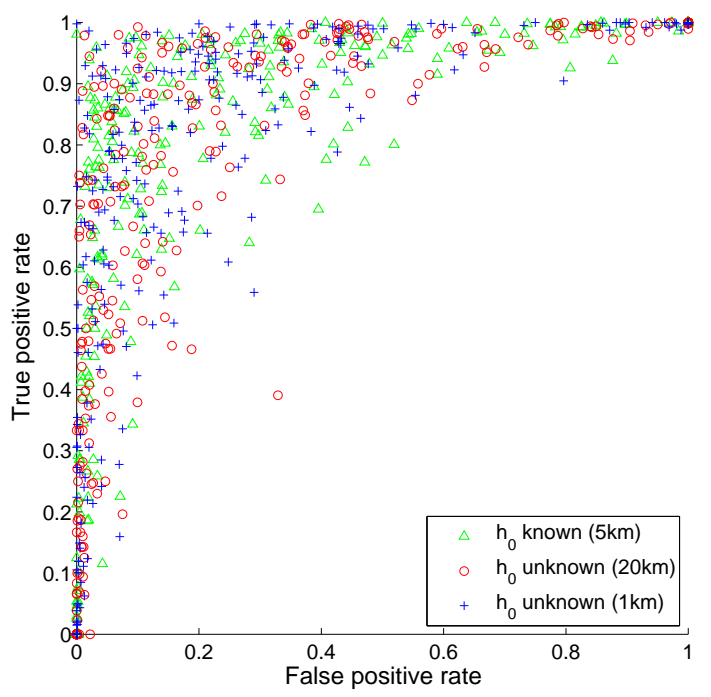

Figure 6: Results of ROC analyses for assuming 20 instruments and using $h_{0}=5 \mathrm{~km}$ for the simulations and the same value for the inversion or $h_{0}=20 \mathrm{~km}$ or $h_{0}=1 \mathrm{~km}$ for the inversion.

are conducted assuming 20 instruments and $h_{0}=5 \mathrm{~km}$ for the simulations but inversion assuming $h_{0}=20 \mathrm{~km}$ or $h_{0}=1 \mathrm{~km}$, which can then be compared to the results when $h_{0}$ is assumed to equal $5 \mathrm{~km}$ (Figure 6). This graph supports the observation made previously that for $h_{0}$ within the range 5 (or even 1 ) to $20 \mathrm{~km}$, which corresponds to the values observed for moderate to large earthquakes in active regions, the exact value used for this parameter is not critical.

\section{Conclusions}

In this brief article, the benefits of installing a (very) dense seismic network in the vicinity of a source of induced seismicity are assessed from the point of view of detecting potentially damaging motions at local buildings. 
The considered scenarios are limited to those that are realistic from the point of view of current monitoring technology, induced ground motions and the latest research on spatial correlations. It is found that installing a local network of a density similar to some recent arrays (e.g. ICEARRAY), i.e. 10 to 20 instruments per $\mathrm{km}^{2}$ would lead to a reasonable detection rate but with the risk of a considerable number of false alarms and missed detections. As the number of sensors increases to densities not yet seen in engineering seismology (50 to 100 instruments per $\mathrm{km}^{2}$ ) the number of missed detections and false alarms decreases significantly. The density of instruments installed is a decision for the EGS operator and the regulatory authority since it is related to the chance of correctly recovering potentially-damaging ground motions that is accepted by these organizations.

The type of study presented here could form part of a wider cost-benefit analysis that seeks to find the optimum number of instruments to install in the vicinity of a project that could induce earthquakes (e.g. an EGS) based on the trade-off between the cost of the instruments and their installation and maintenance and their benefit in terms of the ability to accurately estimate the ground motions at points of interest and also, if the instruments could also be used to locate earthquakes, the improvement in reservoir monitoring. Such an analysis would require, however, estimates on the likely cost of resolving insurance claims, required length of monitoring and so forth, which are difficult aspects to define a priori. For the location of a future project where the locations of the buildings, their overall vulnerabilities to earthquakes and a local ground-motion model are known, a site-specific analysis could be conducted following a similar approach to give more precise guid- 
ance on the installation of a local monitoring network.

The results obtained here are dependent on the value assumed for the spatial correlation length $h_{0}$. As demonstrated by Jayaram and Baker [7] and others $h_{0}$ appears to show a dependency on structural period, earthquake magnitude and geographical region. All previous studies on this parameter focus on its value for moderate and large tectonic earthquakes $\left(M_{w}>5\right)$ in active regions with high instrument densities (predominantly California, Taiwan and Japan) and, therefore, there is uncertainty on the values to use for this key parameter for small induced earthquakes, particularly those occurring in areas with low instrument densities. Therefore, there is a need for additional research on spatial correlation of ground motions from small (induced) earthquakes to better constrain spatial correlation models.

\section{Acknowledgments}

This study was funded by GEISER (Geothermal Engineering Integrating Mitigation of Induced Seismicity in Reservoirs) project funded under contract 241321 of the EC-Research Seventh Framework Programme (FP7). I thank Stefan Wiemer, Falko Bethmann, Dirk Kraaijpoel, Vincenzo Convertito and Ben Edwards for the discussions that led to this study, and their comments on an earlier draft.

\section{References}

[1] E. L. Majer, R. Baria, M. Stark, S. Oates, J. Bommer, B. Smith, H. Asanuma, Induced seismicity associated with En- 
hanced Geothermal Systems, Geothermics 36 (2007) 185-222. doi:10.1016/j.geothermics.2007.03.003.

[2] D. Giardini, Geothermal quake risks must be faced, Nature 462 (2009) 848-849. doi:10.1038/462848a.

[3] B. Halldorsson, S. Ólafsson, J. T. Snæbjörnsson, S. U. Sigurdhsson, R. Rupakhety, R. Sigbjörnsson, On the effects of induced earthquakes due to fluid injection at Hellisheidi geothermal power plant, Iceland, in: Proceedings of Fifteenth World Conference on Earthquake Engineering, 2012, paper no. 4069.

[4] F. O. Strasser, J. J. Bommer, Review: Strong ground motions - Have we seen the worst?, Bulletin of the Seismological Society of America 99 (5) (2009) 2613-2637. doi:10.1785/0120080300.

[5] H. Crowley, P. J. Stafford, J. J. Bommer, Can earthquake loss models be validated using field observations?, Journal of Earthquake Engineering 12 (7) (2008) 1078-1104. doi:10.1080/13632460802212923.

[6] J. Douglas, B. Edwards, B. M. Cabrera, V. Convertito, A. Tramelli, D. Kraaijpoel, N. Maercklin, N. Sharma, G. De Natale, Predicting ground motion from induced earthquakes in geothermal areas, Bulletin of the Seismological Society of AmericaSubmitted.

[7] N. Jayaram, J. W. Baker, Correlation model for spatially distributed ground-motion intensities, Earthquake Engineering and Structural Dynamics 38 (15) (2009) 1687-1708. doi:10.1002/eqe.922. 
[8] B. Halldorsson, R. Sigbjornsson, J. Schweitzer, ICEARRAY: The first small-aperture, strong-motion array in Iceland, Journal of Seismology 13 (2009) 173-178. doi:10.1007/s10950-008-9133-z.

[9] M. D. Trifunac, Recording strong earthquake motion — Instruments, recording strategies and data processing, Tech. Rep. CE 07-03, Department of Civil Engineering, University of Southern California (Sep 2007).

[10] C. B. Worden, M. C. Gerstenberger, D. A. Rhoades, D. J. Wald, Probabilistic relationships between ground-motion parameters and Modified Mercalli intensity in California, Bulletin of the Seismological Society of America 102 (1) (2012) 204-221. doi:10.1785/0120110156.

[11] J. R. Carr, C. E. Glass, Use of geostatistics for accurate mapping of earthquake ground motion, Geophysical Journal 97 (1) (1989) 31-40.

[12] N. N. Ambraseys, J. Douglas, Magnitude calibration for north Indian earthquakes, Geophysical Journal International 159 (1) (2004) 165-206. doi:10.1111/j.1365-246X.2004.02323.x.

[13] J. Douglas, Inferred ground motions on Guadeloupe during the 2004 Les Saintes earthquake, Bulletin of Earthquake Engineering 5 (3) (2007) 363-376. doi:10.1007/s10518-007-9037-2. 